\title{
Protective effects of a cystine and theanine mixture against acute radiation injury in rats
}

Mutsumi Matsuu-Matsuyama ${ }^{\text {a, }}{ }^{*}$, Kazuko Shichijo ${ }^{\text {, }}$, Takashi Tsuchiya ${ }^{\text {c }}$, Hisayoshi Kondo ${ }^{\text {d, Shiro }}$ $\operatorname{Miura}^{\mathrm{e}}$, Katsuya Matsuda ${ }^{\mathrm{b}}$, Ichiro Sekine ${ }^{\mathrm{b}}$ and Masahiro Nakashima ${ }^{\mathrm{a}, \mathrm{b}}$

a Tissue and Histopathology Section, b Department of Tumor and Diagnostic Pathology, d Biostatistics Section, Atomic Bomb Disease Institute, Nagasaki University, 1-12-4 Sakamoto, Nagasaki 852-8523, Japan, ${ }^{c}$ Sendai City Medical Center, 5-22-1 Tsurugaya, Miyagino, Miyagi

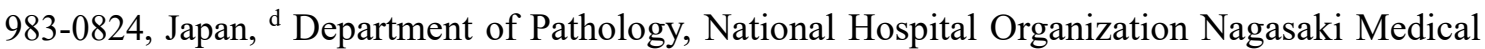
Center, 2-1001-1 Kubara, Omura, Nagasaki 856-8562, Japan.

*Corresponding author. 1-12-4 Sakamoto, Nagasaki 852-8523, Japan. Tel: +81 95819 7107; Fax: +81958197108.

E-mail address: mutsumi@nagasaki-u.ac.jp (M. Matsuu-Matsuyama), shichijo@,nagasaki-u.ac.jp (K.

Shichijo), tsuchiya@openhp.or.jp (T. Tsuchiya), hkondo@,nagasaki-u.ac.jp (H. Kondo),

miura.shiro.kn@mail.hosp.go.jp (S. Miura), katsuya@nagasaki-u.ac.jp (K. Matsuda), i-sekine@,nagasaki-u.ac.jp (I. Sekine), moemoe@,nagasaki-u.ac.jp (M. Nakashima) 


\section{Abstract}

This study aims to examine the effects of cystine and theanine (CT), which increases glutathione biosynthesis, on the survival rate and acute radiation injury of the small intestine and bone marrow using a rat model. CT pre-treatment $(280 \mathrm{mg} / \mathrm{kg}$ for 5 days) significantly improved weight loss and survival rate of rats as compared with the control group after 5 Gy. CT pre-treatment significantly increased the rate of mucosa and crypt length, and decreased the number of apoptotic cells, TUNEL and cleaved caspase- 3 positive cells, while increasing the number of mitotic cells and Ki-67 positive cells in jejunal crypts and villi compared to control rats post-irradiation. CT also suppressed bone marrow cell loss and reduced the number of apoptotic cells in bone marrow. These results suggest a protective effect of CT pre-treatment for acute injury after irradiation through apoptosis inhibition and increased proliferative activity in jejunal crypt cells and bone marrow cells.

${ }^{1}$ Keywords: Cystine and Theanine, Jejunum, Bone marrow, Apoptosis, Radiation

1 Abbreviations: GSH, glutathione; CT, cystine and theanine; ROS, reactive oxygen species;

TUNEL, terminal deoxynucleotidyl transferase (TdT)-mediated dUTP nicked labeling; GSSG, glutathione-S-S-glutathione 


\section{Introduction}

Acute intestinal injury and bone marrow suppression are well known as serious, life-threatening effects induced by whole-body high-dose radiation. Hematopoietic syndrome can occur after whole-body irradiation at a dose of 2 Gy or higher, which reduces leukocyte and platelet numbers and causes bone marrow suppression, resulting in death within 30 days of exposure (Kirsch et al., 2010; Mettler and Voelz, 2002). At higher doses of $10 \mathrm{~Gy}$, death occurs within ten days as a result of damage to the gastrointestinal tract (Kirsch et al., 2010; Mason et al., 1989). Exposure to ionizing radiation generates an increase of reactive oxygen species (ROS) (Mikkelsen and Wardman, 2003) and results in rapid apoptosis in bone marrow cells (Singh et al., 2017) and intestinal crypt cells (Potten and Grant, 1998; Potten 2004), which undergo high cell turnover rate. Exposure to high doses of radiation can severely reduce hematopoietic stem cells and bone marrow progenitor cells (Singh et al., 2017). Crypt disturbance results from cell loss by apoptosis and the destruction of the stem cells in the crypts, which are responsible for repopulating the lining (Potten et al., 2009). High doses of ionizing radiation damage intestinal crypt cells, and result in shortening of the mucosal length, as well as functional changes. These deleterious effects, including malabsorption, are seen clinically as acute small bowel reactions. Further pharmacological development is required to protect against the toxicity of ionizing radiation. 
It is reported that ionizing radiation-induced cell death is regulated via a p53-dependent pathway in the gastrointestinal tract (Merritt et al., 1997). Caspase-3 activation is a major effector in the apoptotic process following irradiation of intestinal cells and bone marrow cells (Marshman et al., 2001; Segreto et al., 2011). Previously, we have reported that polaprezinc, which is an anti-ulcer agents and a chelating compound consisting of zinc ion and L-carnosine, and basic fibroblast growth factor (bFGF) exert protective effects on radiation-induced apoptosis in the small intestine of rats (Matsuu-Matsuyama et al., 2008; Matsuu-Matsuyama et al., 2010). Both agents could suppress radiation-induced apoptosis and the p53 pathway in intestinal crypt cells at an early stage within $24 \mathrm{~h}$ post-irradiation.

Cystine is a sulfur-containing amino acid consisting of two cysteine molecules connected by an S-S bond. Cystine is a precursor of glutathione (GSH), which is responsible for anti-oxidative reactions in the body, and the supply of cysteine is rate-limiting to GSH synthesis (Kurihara et al., 2007). Theanine (gamma-glutamylethylamide), an amino acid found abundantly in green tea, is metabolized to glutamic acid and ethylamine in the intestine or liver (Shibakusa et al., 2012). It has been reported that oral administration of $\mathrm{CT}$ enhanced immune function in a mouse surgical model of the small intestine through GSH synthesis (Kurihara et al., 2007, 2013). GSH plays an important role in counteracting oxidative stress induced by ionizing radiations (Mikkelsen and Wardman, 2003; Jagetia, 2007). It is expected that CT exerts protective effects against radiation-induced injury 
through an anti-oxidative effect. Patt et al. were the first to investigate effects of the amino-acid

cysteine in rats exposed to lethal doses of X-rays (800 R) (Patt et al., 1949). It has been reported that cysteine administered orally before LD50/30 total body irradiation (750 R) produced a protective

effect against acute radiation effects in mouse splenic lymphocytes (Bari et al., 1968).

In this study, to examine the protective effects of CT against acute radiation-induced injury, we investigated the effects of CT pre-treatment on survival rate after 5 Gy X-ray total body irradiation. We examined the effect of $\mathrm{CT}$ pre-treatment on acute radiation injury of rat small intestine and bone marrow, histologically. We then observed the effect of CT on apoptosis, mitosis, and proliferation of small intestinal crypt cells and the apoptosis of bone marrow cells after irradiation.

\section{Materials and methods}

\subsection{Animals}

Seven-week-old male Wistar rats (Charles River Japan, Atsugi, Japan) were used for the present study. All animals were kept in specific pathogen-free conditions at the Nagasaki University Animal Center and allowed free access to food and tap water. They were orally treated with a mixture of CT (C:T=5:2) (Ajinomoto Co., Inc., Tokyo, Japan), which was suspended in $0.5 \%$ carboxymethyl cellulose solution (CMC) (FUJIFILM Wako Pure Chemical Corporation, Osaka, Japan) at $280 \mathrm{mg} / \mathrm{kg}$ body weight/day. The non-treated control group received $0.5 \% \mathrm{CMC}$ only. All treatments were 
performed for five days before irradiation. Irradiated animal groups received whole-body irradiation using a Toshiba ISOVOLT TITAN32 X-ray, at $200 \mathrm{kV}$ at a dose rate of $0.5531 \mathrm{~Gy} / \mathrm{min}$. A single dose of 2 or 5 Gy was administered. Non-irradiated groups $(0 \mathrm{~h}$ or $0 \mathrm{~d})$ were not irradiated, but were otherwise handled identically. This experimental protocol was approved by the Institutional Animal Care and Use Committee at Nagasaki University Animal Center (protocol No. \#1606161315). This study protocol adhered to the ARRIVE guidelines.

\subsection{Survival rate}

The body weight was measured, and the survival of the CT-treated and control rats were determined by observations every $24 \mathrm{~h}$ for 28 days after 5 Gy irradiation. The rate of change of body weight and survival rate were compared between post-irradiation and pre-irradiation conditions.

\subsection{Histopathologic examination}

All animals were sacrificed by deep anesthesia at each time point ( $3 \mathrm{~h}, 6 \mathrm{~h}, 24 \mathrm{~h}(1 \mathrm{~d}), 48 \mathrm{~h}(2 \mathrm{~d})$, $72 \mathrm{~h}(3 \mathrm{~d})$, and $168 \mathrm{~h}(7 \mathrm{~d}))$ after irradiation. Each jejunum and spine, including bone marrow, was resected, and immersed in neutral-buffered formalin, and routinely embedded in paraffin blocks. Spines were decalcified in EDTA for 20-30d after fixation. Sections were used for counting the number of mitotic figures and apoptotic cells with hematoxylin and eosin (H\&E) stain, 
immunohistochemistry, and TUNEL method.

Mucosa length, defined as the length from the apex of the brush border to the base of the crypt in the jejunum, and crypt depth (along the long axis of the elliptical crypt) were measured in H\&E-stained section using a $100 \times$ magnification captured with light microscopy and a digital camera system (Keyence BZ-9000E, Keyence Co., Osaka Japan). The length of more than five random mucosa or crypt were measured, and the rate of the measured length of mucosa or crypt after irradiation was averaged per animal. Scoring of apoptotic and mitotic figures in the jejunum was restricted to good longitudinal sections of the crypt, in which the base of the crypt was aligned with all other crypt bases, indicating the crypt lumen. More than 30 longitudinal crypt sections were selected per animal, and apoptotic and mitotic cells were scored in each crypt in H\&E-stained sections at $400 \times$ magnification by light microscopy, as described previously (Matsuu-Matsuyama et al., 2010). Bone marrow cells were counted in five areas per animal in H\&E-stained sections at 200× magnification captured with light microscopy and a digital camera system (Nikon Camera Control Unit DS-L2, Nikon Co., Tokyo, Japan), and the measurements were averaged per animal. To assess the blood component, blood samples were collected from hearts of rats under deep anesthesia. Blood was collected from CT pre-treated rats and control rats 3 and 7 days after 5 Gy irradiation. Blood samples were also collected from non-irradiated CT pre-treated rats and control rats. Analysis of the number of red blood cells (RBC), white blood cells (WBC), and platelets (PLT) was performed in 
LSI Medience Corporation (Tokyo, Japan).

\subsection{Immunohistochemistry}

Immunohistochemical staining was performed for Ki-67 and cleaved caspase-3. Slides were stained as described previously (Matsuu-Matsuyama et al., 2010). Anti-rat Ki-67 monoclonal antibody (MIB-5) (Agilent Dako, CA, USA) and cleaved caspase-3 antibody (Cell Signaling Technology Inc., MA, USA) were used. The secondary antibody, LSAB-2 system-HRP for use on rat specimens (Agilent Dako, CA, USA), was used according to the manufacturer's instructions. Cells showing immunoreactivity for Ki-67 and cleaved caspase-3 were counted in more than 30 crypts and 50 villi of the jejunum per rat at $400 \times$ magnification using light microscopy. The cleaved caspase-3 positive bone marrow cells were counted in five or six areas from four rats in every group at $400 \times$ magnification captured with light microscopy and a digital camera system (Nikon Camera Control Unit DS-L2).

\subsection{TUNEL method}

Apoptosis was confirmed using a TUNEL technique (Apoptag Peroxidase In Situ Apoptosis Detection Kit, EMD Millipore Co., CA, USA) that detects apoptosis-associated DNA fragmentation by labeling the 3 ' $-\mathrm{OH}$ termini with digoxigenin nucleotides using terminal deoxynucleotidyl 
transferase. Slides were stained as described previously (Matsuu-Matsuyama et al., 2010). TUNEL

positive cells were counted in more than 30 crypts and 50 villi of the jejunum per rat at $400 \times$ magnification using light microscopy. TUNEL positive bone marrow cells were counted in five or six areas per rat at $400 \times$ magnification captured with light microscopy and a digital camera system (Nikon Camera Control Unit DS-L2).

\subsection{Statistics}

A Wilcoxon test was employed for Kaplan-Meier survival analysis. The rate of change of the mucosal and crypt length, the number of bone marrow cells, and the values of RBC, WBC, and PLT were expressed as the means \pm SEM of results obtained from three to six animals per data point. The number of apoptotic cells, TUNEL, cleaved caspase-3, mitotic cells, and Ki-67 positive cells were expressed as the means \pm SEM of results obtained from pooled data from three to six animals per data point.

Differences between CT-treated and control groups were examined using Mann-Whitney $U$ test. Statistical analyses were conducted using SAS statistical software (SAS Institute Inc., NA, USA) and Bell Curve for Excel (Social Survey Research Information Co., Ltd., Tokyo, Japan). $p$ values less than 0.05 were considered statistically significant. 


\section{Results}

3.1. Survival rate and alterations of body weight

A total of 45 animals, including CT-treated $(n=23)$ and control $(n=22)$ groups, were analyzed.

Body weight changes and survival rates of CT pre-treated rats and control rats are shown in Fig. 1.

Body weight changes in the CT pre-treated group was significantly higher than that of the control group at 10,12,14, and 28 days after 5 Gy irradiation (Fig. 1A). The survival rate of CT pre-treated rats increased compared to that of control rats ( $78.3 \%$ vs. $54.5 \%, p=0.0434)$ (Fig. 1B).

\subsection{Histopathology of the jejunum}

For histopathology, a total of 129 animals, including CT-treated $(n=64)$ and control $(n=65)$ groups, were analyzed. Figure 2 shows the rate of mucosa and crypt length changes after 5 Gy irradiation. The mucosa length of the control group at $3 \mathrm{~d}$ was $85.5 \pm 4 \%$ lower than that at $0 \mathrm{~d}$, but results in the CT group were $98.4 \pm 3.8 \%$ lower than that at $0 \mathrm{~d}$. The mucosa length of controls at $7 \mathrm{~d}$ was $119.5 \pm 3 \%$ greater than at $0 \mathrm{~d}$, while results of the CT group were $134.5 \pm 3.7 \%$ greater than that at $0 \mathrm{~d}$. Mucosa length significantly differed between control and CT groups at 3 and $7 \mathrm{~d}$ (Fig. 2A). At $3 \mathrm{~d}$, the crypt length increased by $132.1 \pm 3.7 \%$ and $147.5 \pm 5.1 \%$ compared to $0 \mathrm{~d}$ in control and CT groups, respectively. Crypt length differed significantly between control and CT groups at $3 \mathrm{~d}$ after irradiation (Fig. 2B). At $2 \mathrm{~Gy}$, the rate of change of the mucosal and crypt length were lower 
compared to observations at $5 \mathrm{~Gy}$, there was no significant difference in mucosal and crypt length between control and CT groups (Suppl. Fig. 1). The pre-treatment of CT suppressed mucosal length decrease, while increasing crypt length after 5 Gy irradiation.

Figure 3 shows the number of apoptotic figures per crypt detected by H\&E staining, and the number of TUNEL positive cells and cleaved caspase-3 positive cells per jejunal crypt and villi after 5 Gy irradiation. Apoptotic cells significantly decreased in the CT-pretreated group at 3,6, 24, and $72 \mathrm{~h}$ compared to the control group after 5 Gy irradiation (Fig. 3A). CT-pretreatment significantly decreased the number of TUNEL positive cells in crypts at 3,72, and $168 \mathrm{~h}$ compared to the control group after irradiation (Fig. 3B). Cleaved caspase-3 positive cells in crypts in the CT-treatment group significantly decreased at 3 and $6 \mathrm{~h}$ compared to the control group (Fig. 3C). In the mesenchymal cells of the villi, CT-pretreatment significantly decreased the number of TUNEL positive cells at $72 \mathrm{~h}$ compared to controls after irradiation. The number of cleaved caspase- 3 positive cells decreased at $3 \mathrm{~h}$ (Fig. 3D, E). At 2 Gy, the number of apoptotic figures and TUNEL positive cells per crypt in the CT-treatment group decreased at 3, 6, and $24 \mathrm{~h}$ compared to the control group after irradiation (Suppl. Fig. 2A, B). In villi, the number of TUNEL positive cells in the CT-treatment group was decreased at $24 \mathrm{~h}$ compared to the control group (Suppl. Fig. 2C).

Figure 4 shows the number of mitotic cells per crypt detected by H\&E staining, and the number of Ki-67 positive cells per crypt and mesenchymal cells of villi after 5 Gy irradiation. 
CT-pretreatment significantly increased the number of mitotic cells in the jejunal crypt at $24 \mathrm{~h}$ after 5 Gy irradiation (Fig. 4A). The number of Ki-67 positive cells was significant higher in crypts and villi in the non-irradiated CT-treated group compared to the control group $(0 \mathrm{~h})$. Further, CT-pretreatment significantly increased Ki-67 positive cells in crypts at 3, 6, 24, 72, and $168 \mathrm{~h}$ compared to the control group after 5 Gy irradiation (Fig. 4B). In villi, CT-pretreatment significantly increased Ki-67 positive cells at $168 \mathrm{~h}$ compared to the control group after 5 Gy irradiation (Fig. 4C). At 2 Gy, CT-pretreatment significantly increased mitotic cells in jejunal crypts at 6 and $168 \mathrm{~h}$ (Suppl.Fig. 3A). The number of Ki-67 positive cells was significantly higher in the CT-treated group compared to the control group at $0,6,24,72$, and $168 \mathrm{~h}$ (Suppl. Fig. 3B). In mesenchymal cells, CT-pretreatment significantly increased the number of Ki-67 positive cells at 3 and $6 \mathrm{~h}$ after 2 Gy irradiation (Suppl. Fig. 3C).

\subsection{Histopathology of bone marrow}

To examine the effect of CT-pretreatment on survival rate, blood and bone marrow were investigated by histological examination. Table 1 shows the results of RBC, WBC, and PLT levels after 5 Gy irradiation. The number of RBCs in both groups decreased at $7 \mathrm{~d}$ after irradiation. The number of WBCs in both groups decreased dramatically at $3 \mathrm{~d}$, and this decrease continued until $7 \mathrm{~d}$ post-irradiation. The number of PLTs in both groups also decreased at $7 \mathrm{~d}$ after irradiation. There 
was no difference in the number of RBCs and PLTs between control and CT-treatment groups at 3

and $7 \mathrm{~d}$ after irradiation. The number of WBCs was slightly higher in the CT-treatment group compared to the control group at $7 \mathrm{~d}$ post-irradiation, but not significantly. Figure 5 shows the morphological changes of the bone marrow and the number of bone marrow cells after irradiation. Bone marrow cells decreased dramatically at $3 \mathrm{~d}$, and there were few bone marrow cells in both groups. However, the bone marrow cells of the CT pre-treatment group appeared at $7 \mathrm{~d}$, while bone marrow cells of the CT-treated group was significantly higher compared to control rats at $7 \mathrm{~d}$ after irradiation. Megakaryocyte cells decreased gradually until $7 \mathrm{~d}$ post-irradiation in both groups. There was no significant difference between the CT-treatment group and the control group at each time point (data not shown).

Figure 6 shows the number of TUNEL and cleaved caspase- 3 positive bone marrow cells after 5 Gy irradiation. In the CT-treated group, the number of TUNEL positive cells and cleaved caspase-3 positive cells significantly decreased after 5 Gy irradiation at $6 \mathrm{~h}$ and $3 \mathrm{~h}$ respectively (Fig.6A, B).

\section{Discussion}

The protective effect of $\mathrm{CT}$ was evaluated by analyzing the survival rate and acute radiation injury of bone marrow and the small intestine of rats exposed to whole-body radiation. CT pre-treatment significantly improved weight loss and survival rate of rats after whole-body 
irradiation (5 Gy). Bone marrow cells and small intestinal crypt cells, which rapidly proliferate, are the most sensitive to radiation, and radiation-induced apoptosis is the primary cause of damage to the small intestine and bone marrow (Singh et al., 2017; Potten 2004). In this study, the protective effects of CT pre-treatment to protect against mucosa length shortening and increase the crypt length became clear after irradiation. CT could significantly reduce apoptotic cells, TUNEL positive cells, and cleaved caspase-3 positive cells in jejunal crypt cells after irradiation. In the mesenchymal cells of villi, CT-pretreatment could suppress TUNEL positive cells only at $72 \mathrm{~h}$ and cleaved caspase- 3 at $3 \mathrm{~h}$. Since the number of TUNEL positive cells and cleaved caspase- 3 in the CT-treated group are higher than the control group at $6 \mathrm{~h}$, the suppression effect of CT in mesenchymal cells of villi may be lower than that in crypt cells until $24 \mathrm{~h}$. The difference in the number of apoptotic cells, TUNEL positive cells, and cleaved caspase- 3 positive cells may reflect the time lag of caspase activation, apoptotic body processing, and degradation, as caspase- 3 was activated earlier in the apoptotic process than DNA cleavage and cell fragmentation. It has been reported that a delayed increase in ROS after 5 Gy external irradiation induces serious DNA damage in a rat thyroid cell line. Pre- and post-administration of the antioxidant $N$-acetyl-L-Cysteine (NAC), a glutathione precursor, could suppress micronuclei induced by delayed ROS elevation (Kurashige et al., 2017). In this study, apoptosis induced in crypt and mesenchymal cells in jejunum of rats after $24 \mathrm{~h}$ may be attributed to delayed ROS elevation after 5 Gy irradiation, while CT pre-treatment may reduce apoptosis after 24 
h by suppressing delayed ROS elevation, in a similar manner to NAC. CT pre-treatment significantly increased proliferation in jejunum crypt cells at each time point upon irradiation, while in mesenchymal cells of the villi, CT significantly increased proliferation a specified period after irradiation in response to apoptosis suppression after $24 \mathrm{~h}$. Decreased radiation-induced apoptosis and proliferation activation of crypt and mesenchymal cells in CT-treated rats may reflect improved villi and crypt length post-irradiation.

Decreased RBC, WBC, and PLT numbers were not significantly different between the control and CT group post-irradiation. However, the number of bone marrow cells increased at $7 \mathrm{~d}$ in $\mathrm{CT}$ pre-treated rats. CT pre-treatment significantly reduced the number of apoptotic cells and cleaved caspase-3 positive cells in bone marrow. CT pre-treatment suppressed radiation-induced apoptosis in bone marrow, which may reflect improved bone marrow functionality post-irradiation. CT pre-treatment rescued bone marrow cells from apoptosis, this may reflect an improved survival rate post-irradiation. We have previously reported that whole-body X irradiation evokes stimulation of autonomic nervous function and severe intestinal injury, resulting in appetite loss and weight loss (Matsuu et al., 2005). CT protected against radiation-induced apoptosis and activated proliferation in the small intestine and bone marrow of CT pre-treated rats, exhibiting improved body weight and survival rate.

It has been reported that oral administration of CT increased GSH synthesis and that CT intake 
inhibited intense exercise-induced inflammation (Kurihara et al., 2007; Tanaka et al., 2015). Research indicates that cystine suppressed IL-6 production and improved survival rates in a lipopolysaccharide (LPS)-induced sepsis mouse model, and enhanced production of IL-10 by monocytes may be involved in the anti-inflammatory response (Banerjee et al., 2012). It has been reported that redox buffer systems including small molecules (e.g. GSH/GSSG, cysteine/cystine) and proteins (e.g. thioredoxin) are employed for thiol-based redox homeostasis, which is essential for controlling cellular functions, including gene expression, cell cycle progression, and apoptosis (Tang et al., 2019). Furthermore, it has been reported that CT administration improves survival after gut ischemia-reperfusion in mice, and jejunal GSSG, cysteine and glutamic acid levels is higher in the CT than in the vehicle group after reperfusion (Miyakuni et al., 2018). It is conceivable that the protective effects of $\mathrm{CT}$ treatment against radiation-induced apoptosis in the jejunum and bone marrow is due to anti-oxidative effects through GSH synthesis. It is reported that ROS-regulated double strand breaks regulate ATM and p53, which in turn mediate the MAPK family (p38, ERK, and JNK) and regulate, inhibit, or promote oxidative stress (Jin et al., 2015). It has been reported that caffeic acid phenyl ester (CAPE), which is a potent anti-inflammatory agent with the ability to eliminate free radicals, attenuates ionizing radiation-induced intestinal injury through modulation of oxidative stress, apoptosis, and p38 MAPK, in a similar manner to NAC in rats (Jin et al., 2015). It is possible that CT protects against radiation-induced apoptosis through actions similar to CAPE and 
NAC.

The aminothiol compound, amifostine (WR-2721,

S-2-[3-aminopropylamino]ethylphosphorothioic acid), is a chemical radioprotector administered

prior to radiotherapy or chemotherapy treatment in certain cancers to selectively reduce normal tissue damage (Brizel et al., 2000; Kouvaris et al., 2007; Ormsby et al., 2014; Yuhas and Storer, 1969). This drug was approved by the Food and Drug Administration to reduce nephrotoxicity from chemotherapy containing cisplatin and to decrease xerostomia caused due to radiation therapy (Sasse et al., 2006; Singh and Seed, 2019). The cytoprotective mechanism of amifostine involves free-radical scavenging, DNA protection and repair acceleration, and induction of cellular hypoxia (Kouvaris et al., 2007; Singh and Seed, 2019). It has been reported that amifostine can protect from apoptosis after high doses of radiation in mouse spleen and bone marrow (Ormsby et al., 2014). However, it has also been reported that amifostine exerts side effects such as hypotension, nausea, vomiting, a metallic taste during infusion, and occasional allergic reactions including rash, fever, and anaphylactic shock (Kouvaris et al., 2007). Amifostine is usually administered intravenously during radiation therapy (Kouvaris et al., 2007; Singh and Seed, 2019). CT is commercially available and can be easily administered orally in its powder form. A recent study reported that CT is safe for colorectal cancer patients receiving postsurgical adjuvant capecitabine therapy and tended to reduce the incidence rate of diarrhea and hand-foot syndrome (Hamaguchi et al., 2019). CT pretreatment 
potentially prevents intestinal acute radiation injury during clinical radiotherapy for malignancies.

Further studies are required to elucidate the mechanism by which CT protects against radiation-induced damage.

\section{Conclusions}

Our results suggest that $\mathrm{CT}$ pre-treatment improved weight loss and the survival rate of rats.

Additionally, CT exerts a protective effect against acute radiation-induced injury in rat jejunum and bone marrow cells through inhibition of apoptosis and cell proliferation acceleration. CT is commercially available and can be easily administered orally in its powder form. CT pretreatment potentially reduces damage to the gastrointestinal tract during abdominal radiation therapy for malignant tumors.

\section{Acknowledgements}

We would like to thank Editage (www.editage.com) for English language editing.

\section{Funding Sources}

This work was supported by grants of collaboration research with Ajinomoto Co., Inc. and Nagasaki University; the program of the Network-type Joint Usage/Research Center for Radiation 
Disaster Medical Science of Hiroshima University, Fukushima University and Nagasaki University; and this work was also partly supported by JSPS KAKENHI Grant Number 17K00554. 


\section{References}

Banerjee, R. 2012. Redox outside the box: Linking extracellular redox remodeling with intracellular redox metabolism. J. Biol. Chem. 287, 4397-4402.

Bari, W.A. 1968. Cysteine protection against the morphologic effects of X-irradiation on mouse spleen. Path. Microbiol. 32, 205-218.

Brizel, D.M., Wasserman, T.H., Henke, M., Strnad, V., Rudat, V., Monnier, A., Eschwege, F., Zhang, J., Russell, L., Oster, W., Sauer R. 2000. Phase III randomized trial of amifostine as a radioprotector in head and neck cancer. J. Clin. Oncol. 18, 3339-3345.

Hamaguchi, R., Tsuchiya, T., Miyata, G., Sato, T., Takahashi, K., Miura, K., Oshio, H., Ohori, H., Ariyoshi, K., Oyamada, S., Iwase, S. 2019. Efficacy of oral administration of cystine and theanine in colorectal cancer patients undergoing capecitabine-based adjuvant chemotherapy after surgery: a multi-institutional, randomized, double-blinded, placebo-controlled, phase II trial (JORTC-CAM03). Supportive Care in Cancer. https://doi.org /10.1007/s00520-019-05205-1.

Jagetia, G.C. 2007. Radioprotective potential of plants and herbs against the effects of ionizing radiation. J. Clin. Biochem. Nutr. 40, 74-81.

Jin, L.G., Chu, J.J., Pang, Q.F., Zhang, F.Z., Wu, G., Zhou, L.Y., Zhang, X.J., Xing, C.G. 2015. Caffeic acid phenethyl ester attenuates ionize radiation-induced intestinal injury through 
modulation of oxidative stress, apoptosis and p38MAPK in rats. Environ. Toxicol. and Pharmacol. 40, 156-163.

Kirsch, D.G., Santiago, P,M., di Tomaso, E., Sullivan, J.M., Hou, W.S., Dayton, T., Jeffords, L.B., Sodha, P., Mercer, K.L., Cohen, R., Takeuchi, O., Korsmeyer, S.J., Bronson, R.T., Kim, C.F., Haigis, K.M., Jain R.K. and Jacks, T., 2010. p53 controls radiation-induced gastrointestinal syndrome in mice independent of apoptosis. Science 327, 593-596.

Kouvaris, J.R., Kouloulias, V.E., Vlahos, L.J. 2007 Amifostine: The first selective-target and broad-spectrum radioprotector. The Oncologist 12, 738-747.

Kurashige, T., Shimamura, M. Nagayama, Y. 2017. N-Acetyl-L-cycteine protects thyroid cells against DNA damage induced by external and internal irradiation. Radiat. Environ. Biophys. 56, 405-412.

Kurihara, S., Shibahara, S., Arisaka, H., Akiyama, Y. 2007. Enhancement of antigen-specific immunoglobulin G production in mice by co-administration of L-cystine and L-theanine. J. Vet. Med. Sci. 69, 1263-1270.

Kurihara, S., Shibakusa, T., Tanaka, K.A. 2013. Cystine and theanine: amino acids as oral immunomodulative nutrients. Springerplus 2, 635. http://www.springerplus.com/content/2/1/635.

Marshman, E., Ottewell, P.D., Potten, C.S., Watson, A.J. 2001. Caspase activation during spontaneous and radiation-induced apoptosis in the murine intestine. J. Pathol.195, 285-292. 
Mason, K.A., Withers, H.R., McBride, W.H., Davis, C.A., Smathers, J.B., 1989. Comparison of the gastrointestinal syndrome after total-body or total-abdominal irradiation. Radiat. Res. 117, 480-488.

Matsuu, M., Shichijo, K., Ikeda, Y., Ito, M., Naito, S., Okaichi, K., Nakashima, M., Nakayama, T., Sekine, I. 2005. Sympathetic hyperfunction causes increased sensitivity of the autonomic nervous system to whole-body X irradiation. Radat. Res. 163, 137-143.

Matsuu-Matsuyama, M., Shichijo, K., Okaichi, K., Nakayama, T., Nakashima, M., Uemura, T., Niino, D., Sekine, I. 2008. Protection by Polaprezinc against radiation-induced apoptosis in rat jejunal crypt cells. J. Radiat. Res. 49, 341-347.

Matsuu-Matsuyama, M., Nakashima, M., Shichijo, K., Okaichi, K., Nakayama, T., Sekine, I. 2010. Basic fibroblast growth factor suppresses radiation-induced apoptosis and TP53 pathway in rat small intestine. Radiat. Res. 174, 52-61.

Merritt, A.J., Allen, T.D., Potten, C.S., Hickman, J.A. 1997. Apoptosis in small intestinal epithelia from p53-null mice: evidence for a delayed, p53-independent G2/M-associated cell death after gamma-irradiation. Oncogene 14, 2759-2766.

Mettler, F.A. Jr, Voelz, G.L., 2002. Major radiation exposure-what to expect and how to respond. N. Engl. J. Med. 346, 1554-1561.

Mikkelsen, R.B., Wardman, P. 2003. Biological chemistry of reactive oxygen and nitrogen and 
radiation-induced signal transduction mechanisms. Oncogene 22, 5734-5754.

Miyakuni, T., Fukatsu, K., Ri, M., Murakoshi, S., Inoue, Y., Kurihara, S., Takayama, T., Yasuhara, H. 2018. Cystine and Theanine improve survival after gut ischemia-reperfusion. Ann. Nutr. Metab.

73, 131-137.

Ormsby, R.J., Lawrence, M.D., Blyth, B.J., Bexis, K., Bezak, E., Murley, J.S., Grdina, D.J., Sykes, J. 2014. Protection from radiation-induced apoptosis by the radioprotector amifostine (WR-2721) is radiation dose dependent. Cell. Biol. Toxicol. 30, 55-66.

Patt, H.M., Tyree, E.B., Straube, R. L., Smith, D, E. 1949. Cysteine protection against X irradiation. Science 110, 213-214.

Potten, C.S., Grant, H.K. 1998. The relationship between ionizing radiation-induced apoptosis and stem cells in the small and large intestine. Br. J. Cancer 78, 993-1003.

Potten, C.S. 2004. Radiation, the ideal cytotoxic agent for studying the cell biology of tissues such as the small intestine. Radiat. Res. 161, 123-136.

Potten, C.S., Gandara, R., Mahida, Y.R., Loeffler, M., Wright, N.A. 2009. The stem cells of small intestinal crypts: where are they? Cell Prolif. 42, 731-750.

Sasse, A.D., Clark, L.G.O., Sasse, E.C., Clark, O.A.C. 2006. Amifostine reduces side effects and improves complete response rate during radiotherapy: results of a meta-analysis. Int. J. Radiation Oncology Biol. Phys. 64, 784-791. 
Segreto, H.R., Oshima, C.T., Franco, M.F., Sliva, M.R., Egami, M.I., Teixeira, V.P., Segreto, R.A.

2011. Phosphorylation and cytoplasmic localization of MAPK p38 during apoptosis signaling in bone marrow granulocytes of mice irradiated in vivo and the role of amifostine in reducing these effects. Acta Histochemica 113, 300-307.

Shibakusa, T., Mikami, T., Kurihara, S., Chiba, Y., Tsuchiya, T., Miyachi, T., Oyama, A., Tanaka.

K.A., Koyama, N. 2012. Enhancement of postoperative recovery by preoperative oral co-administration of the amino acids, cystine and theanine, in a mouse surgical model. Clin. Nutr. $31,555-61$.

Singh, A., Yashavarddhan, M.H., Kalita, B., Ranjan, R., Bajaj, S., Prakash, H., Gupta, M.L. 2017. Podophyllotoxin and rutin modulates ionizing radiation-induced oxidative stress and apoptotic cell death in mice bone marrow and spleen. Front. Immunol. 8, 183.

Singh, V.K., Seed, T.M. 2019. The efficacy and safety of amifostine for the acute radiation syndrome. Expert Opin. Drug Saf. 18, 1077-1090.

Tanaka, K.A., Kurihara, S., Shibakusa, T., Chiba, Y., Mikami, T. 2015. Cystine improves survival rates in a LPS-induced sepsis mouse model. Clin. Nutr. 34, 1159-1165.

Tang, J.Y., Farooqi A.A., Ou-Yang, F., Hou, M.F., Huang, H.W., Wang, H.R., Li, K.T., Fayyaz, S., Shu, C.W., Chang, H.W. 2019. Oxidative stress-modulating drugs have preferential anticancer effects-involving the regulation of apoptosis, DNA damage, endoplasmic reticulum stress, 
autophagy, metabolism, and migration. Seminars in Cancer Biology 58, 109-117.

Yuhas, J.M., Storer, J.B. 1969. Chemoprotection against three modes of radiation death

in the mouse. Int. J. Radiat. Biol. 15, 233-237.

\section{Figure legends}

Fig.1. Body weight changes observed in control and CT-pretreated groups after 5 Gy irradiation (A).

The data are expressed as means \pm SEM. $n=8-22$ (Control group) and $n=14-23$ (CT group). The survival curves of control and $\mathrm{CT}$ pre-treated groups after irradiation (B). $\mathrm{n}=22$ (Control group) and $\mathrm{n}=23(\mathrm{CT}$ group $) * p<0.05$ vs control group.

Fig.2. Histological sections of the jejunum in control and CT-pretreated groups after 5 Gy irradiation subjected to hematoxylin and eosin staining $(\times 100)$. The rate of mucosa $(A)$ and crypt $(B)$ length after 5 Gy irradiation. The data are expressed as means \pm SEM of four to six rats per data point. ${ }^{*} p<0.05$ vs. control group.

Fig.3. The number of apoptotic cells per crypt after 5 Gy irradiation (A). The number of TUNEL positive cells per crypt (B) and villi (D) after irradiation. The number of cleaved caspase-3 positive cells per crypt (C) and villi (E) after irradiation. The data are expressed as means \pm SEM of $\mathrm{n}=125-262$ crypts and $\mathrm{n}=188-266$ villi from four rats. ${ }^{*} p<0.05,{ }^{* *} p<0.01$ and ${ }^{* * *} p<0.001$ vs. control group. 
Fig.4. The number of mitotic cells per crypt after 5 Gy irradiation (A). The number of Ki-67 positive cells per crypt (B) and villi (C) after irradiation. The data are expressed as means \pm SEM of $\mathrm{n}=125-244$ crypts and $\mathrm{n}=200-215$ villi from four rats. ${ }^{*} p<0.05,{ }^{* *} p<0.01$ and ${ }^{* * *} p<0.001$ vs. control group.

Fig.5. Histologic sections of the bone marrow in control and CT-pretreated groups at 3 and $7 \mathrm{~d}$ after 5 Gy irradiation subjected to hematoxylin and eosin staining $(\times 200)$. Mk: megakaryocyte. The number of bone marrow cells per area. The data are expressed as means \pm SEM of four to six rats per data point. ${ }^{*} p<0.05$ vs. control group.

Fig.6. TUNEL and cleaved caspase- 3 positive bone marrow cells after 5 Gy irradiation $(\times 400)$. The number of TUNEL positive cells per area after 5 Gy irradiation (A). The number of cleaved caspase- 3 positive cells per area after 5 Gy irradiation (B). The data are expressed as means \pm SEM of 23-26 area from four rats. ${ }^{*} p<0.05,{ }^{* *} p<0.01$ and ${ }^{* * *} p<0.001$ vs. control group.

Suppl. Fig.1. Histological sections of the jejunum in control and CT-pretreated groups after 5 Gy irradiation subjected to hematoxylin and eosin staining $(\times 100)$. The rate of mucosa (A) and crypt $(\mathrm{B})$ length after 2 Gy irradiation. The data are expressed as means \pm SEM of three to five rats per data point.

Suppl. Fig.2. The number of apoptotic cells per crypt after 2 Gy irradiation (A). The number of TUNEL positive cells per crypt (B) and villi (C) after 2 Gy irradiation. The data are expressed as 
means \pm SEM of $153-252$ crypts and 297-494 villi from three to five rats. ${ }^{*} p<0.05$, ${ }^{* *} p<0.01$ and $* * * p<0.001$ vs. control group.

Suppl. Fig.3. The number of mitotic cells per crypt after 2 Gy irradiation (A). The number of Ki-67 positive cells per crypt (B) and villi (C) after 2 Gy irradiation. The data are expressed as means \pm SEM of $\mathrm{n}=92-213$ crypts and $\mathrm{n}=130-215$ villi from three to five rats. ${ }^{*} p<0.05,{ }^{*} p<0.01$ and $* * * p<0.001$ vs. control group. 


\section{Table 1}

Changes observed in red blood cells (RBC), white blood cells (WBC), and platelets numbers in CT pre-treated and control groups after 5 Gy irradiation.

\begin{tabular}{|c|c|c|c|c|c|}
\hline & Time (d) & Control & $\mathrm{n}$ & $\mathrm{CT}$ & $\mathrm{n}$ \\
\hline $\mathrm{RBC}$ & 0 & $733.5 \pm 8.6$ & 6 & $750 \pm 22.9$ & 5 \\
\hline \multirow[t]{2}{*}{$\left(\times 10^{4} / \mu \mathrm{l}\right)$} & 3 & $742.6 \pm 23.8$ & 5 & $732.3 \pm 24$ & 4 \\
\hline & 7 & $670.2 \pm 19$ & 5 & $676.5 \pm 4.7$ & 6 \\
\hline \multirow[t]{3}{*}{$\mathrm{WBC}(/ \mu \mathrm{l})$} & 0 & $4700 \pm 407.4$ & 6 & $4120 \pm 592.8$ & 5 \\
\hline & 3 & $400 \pm 137.8$ & 5 & $350 \pm 86.6$ & 4 \\
\hline & 7 & $180 \pm 20$ & 5 & $250 \pm 22.4$ & 6 \\
\hline \multirow[t]{3}{*}{$\operatorname{PLT}\left(\times 10^{4} / \mu 1\right)$} & 0 & $99.3 \pm 5.3$ & 6 & $100.1 \pm 9.1$ & 5 \\
\hline & 3 & $98.9 \pm 3.9$ & 4 & $87 \pm 6.7$ & 4 \\
\hline & 7 & $4.6 \pm 0.4$ & 5 & $7.5 \pm 1.5$ & 3 \\
\hline
\end{tabular}

Values are expressed as mean \pm SEM; WBC, white blood cells, RBC, Red blood cells, PLT, platelets 
A

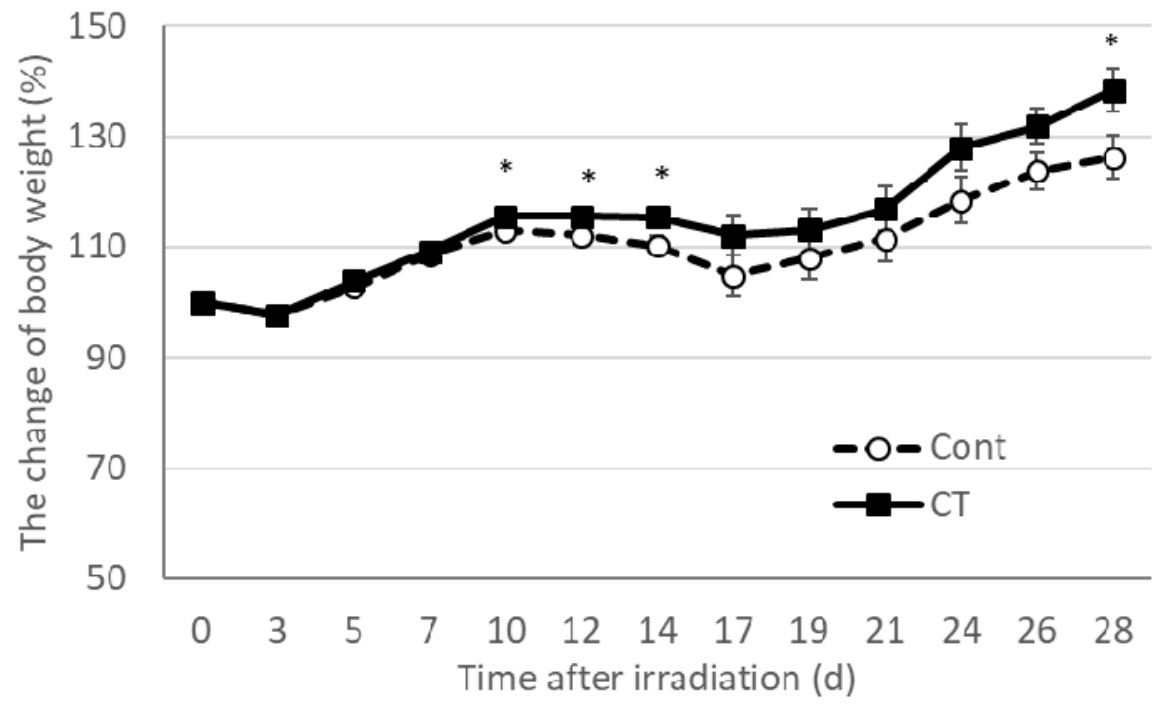

B

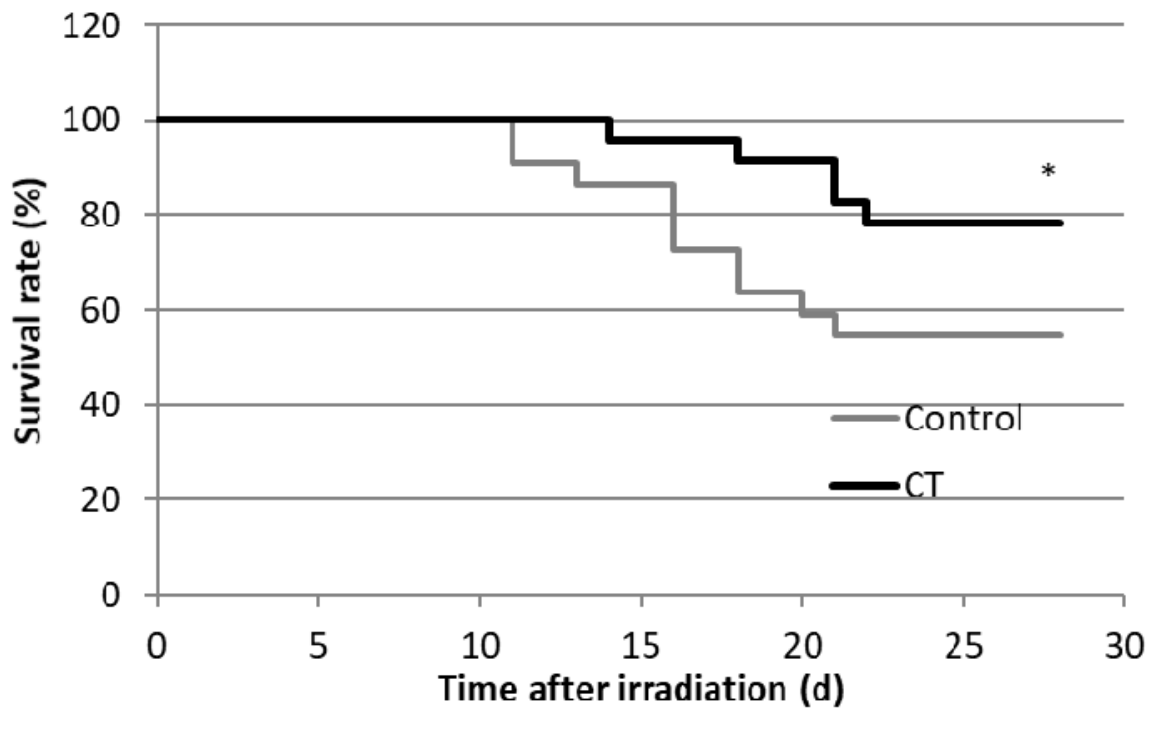

Fig.1 

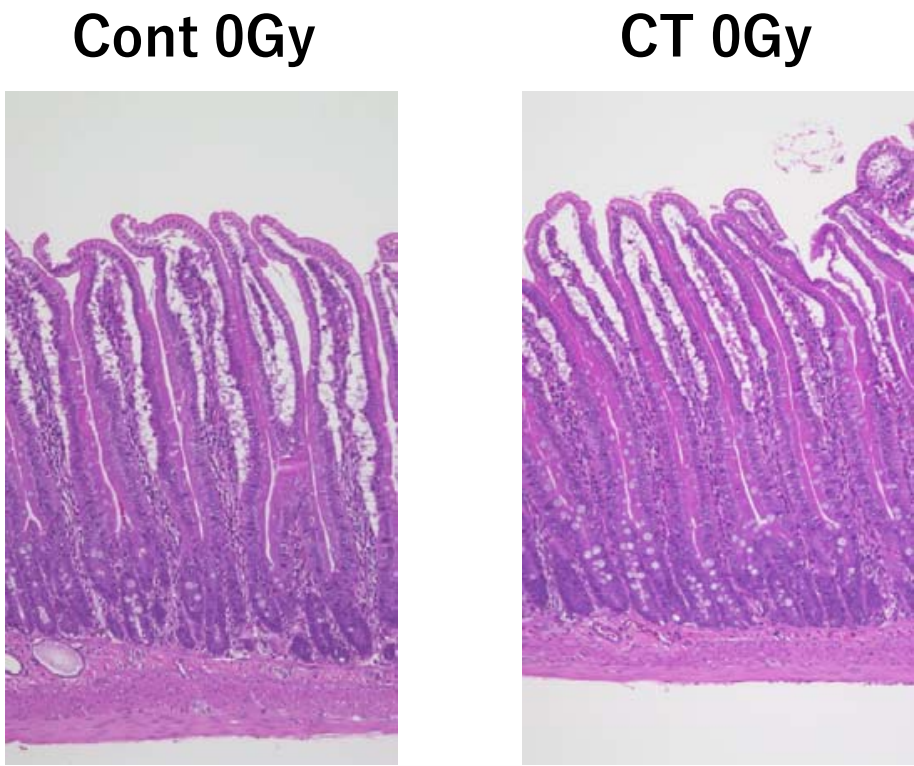

A

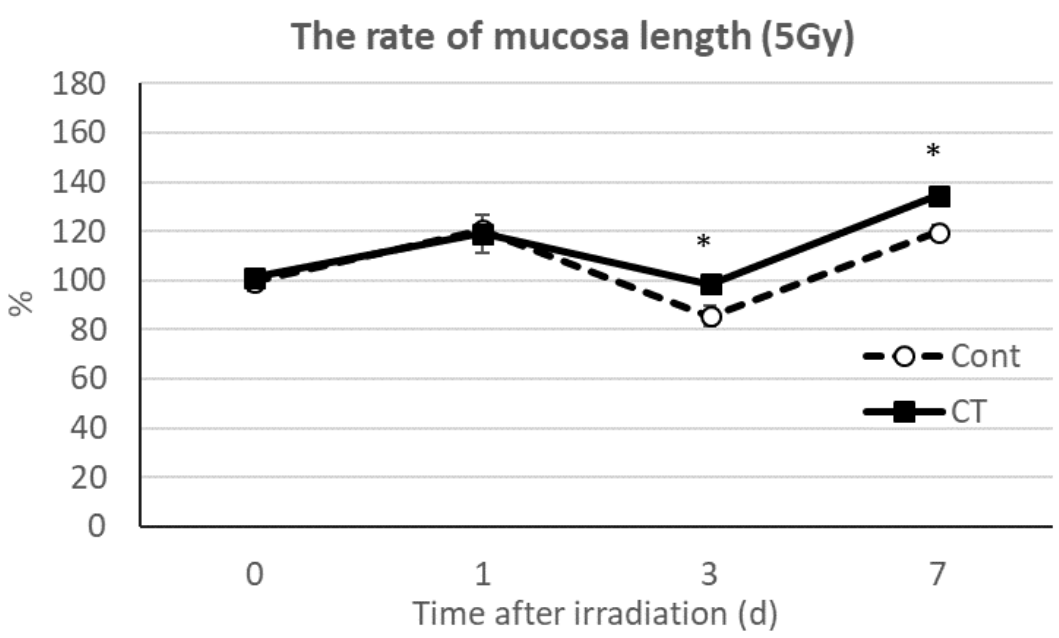

Cont 5Gy3d

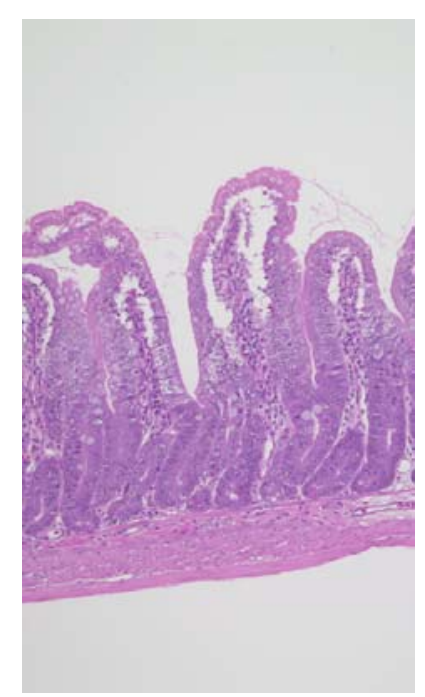

CT 5Gy3d

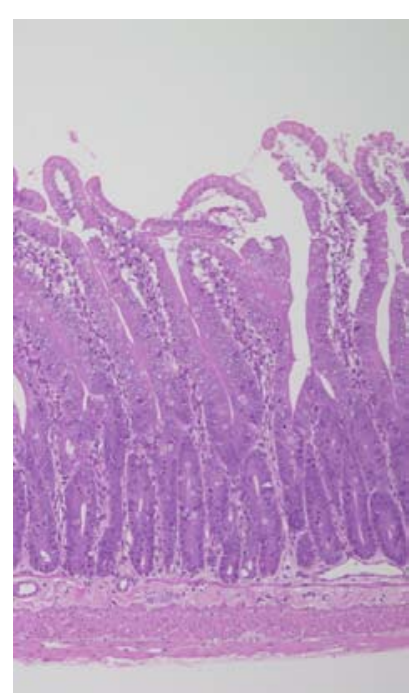

B

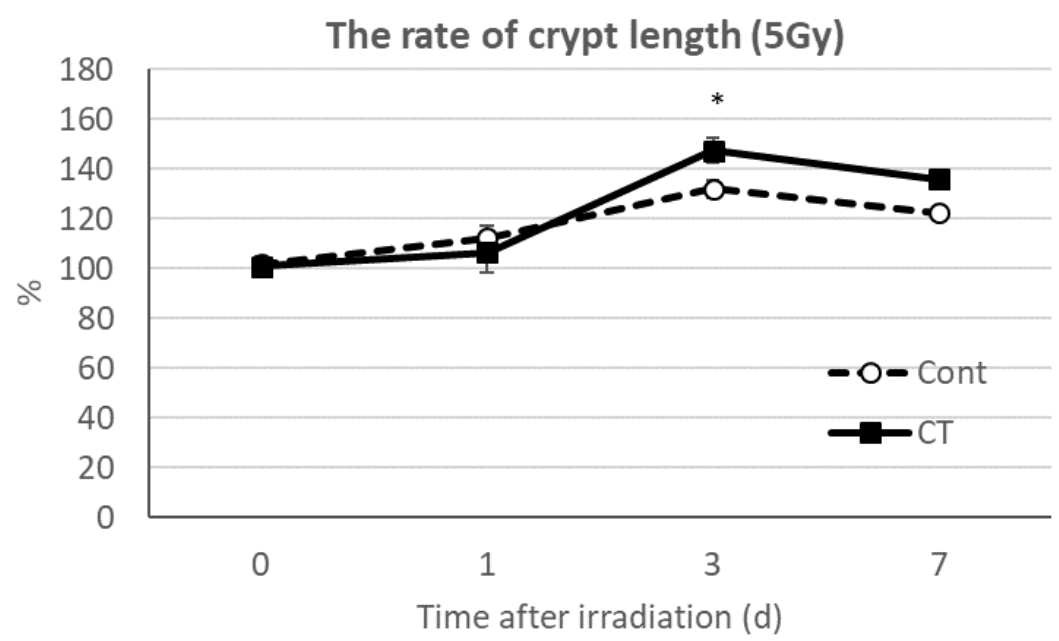

Fig.2 
Apoptosis

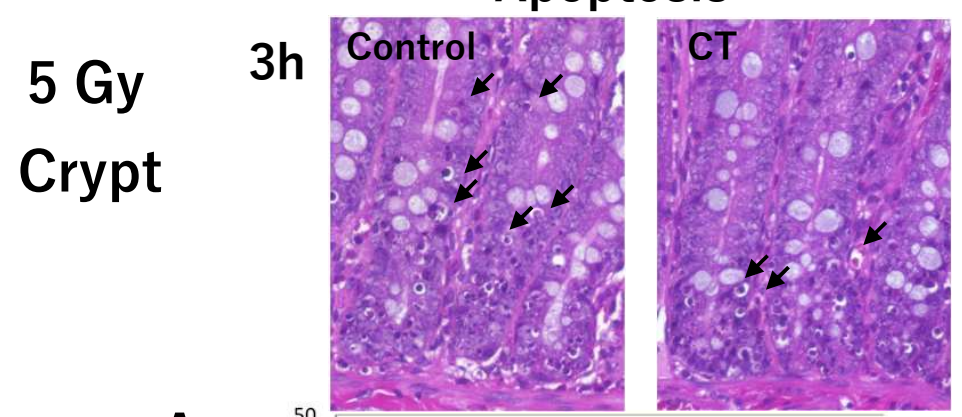

A

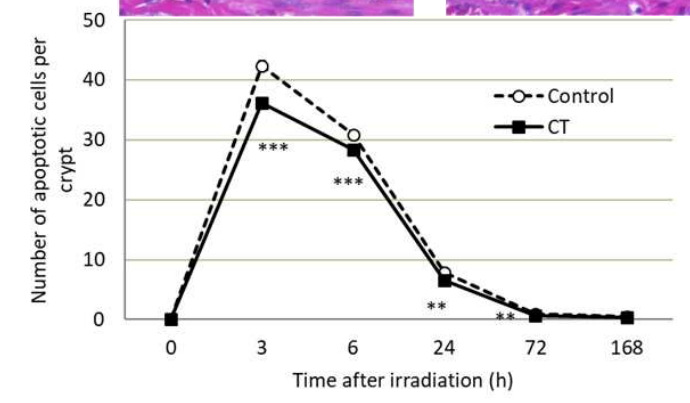

$3 h$

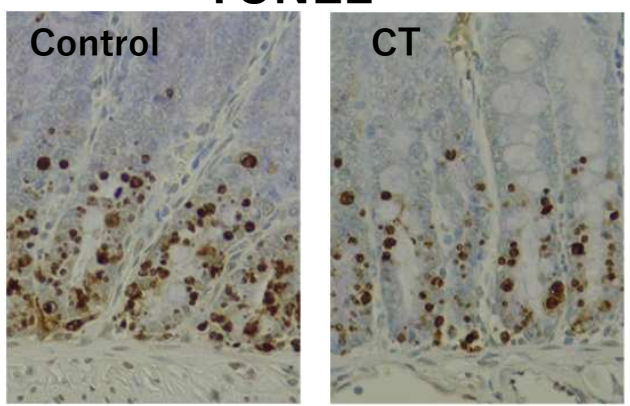

B

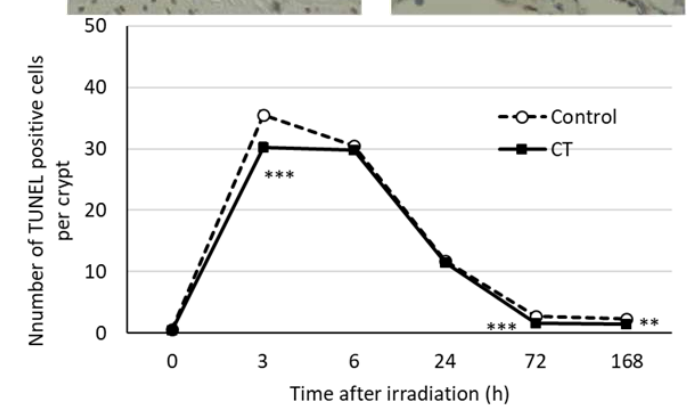

Vill
Fig.3
TUNEL

Cleaved caspase-3

$3 \mathrm{~h}$

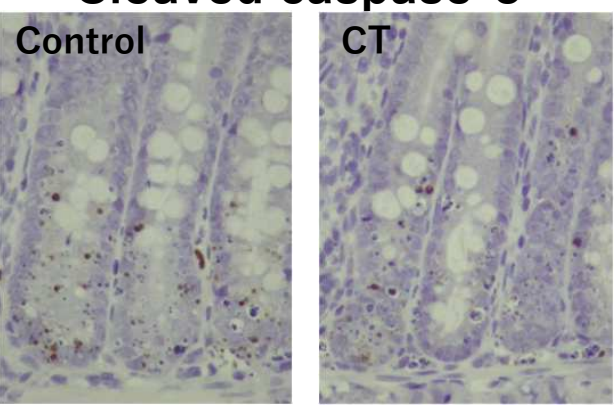

C

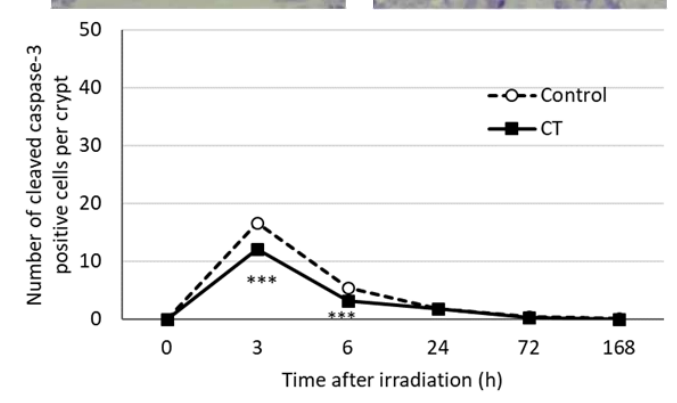

$3 h$
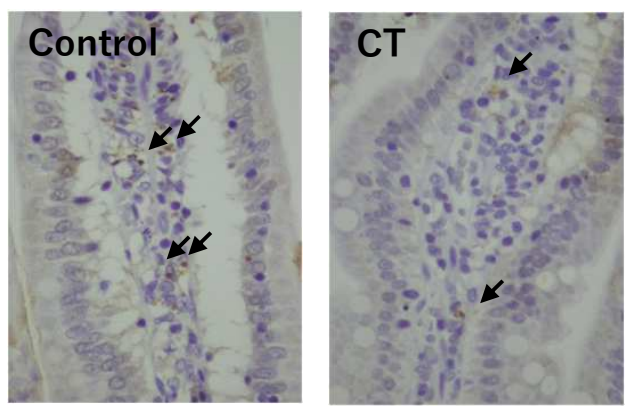

D

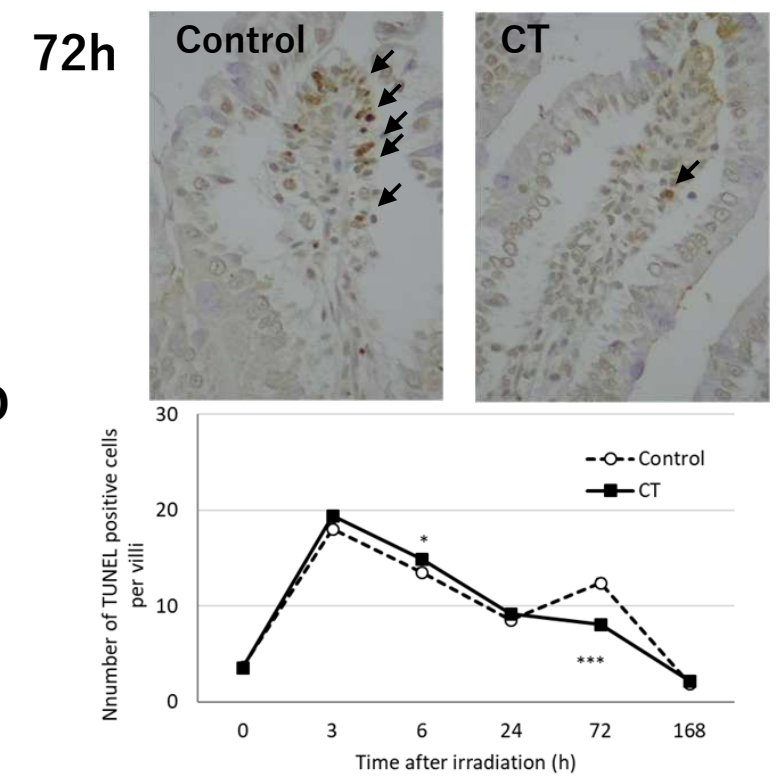

E

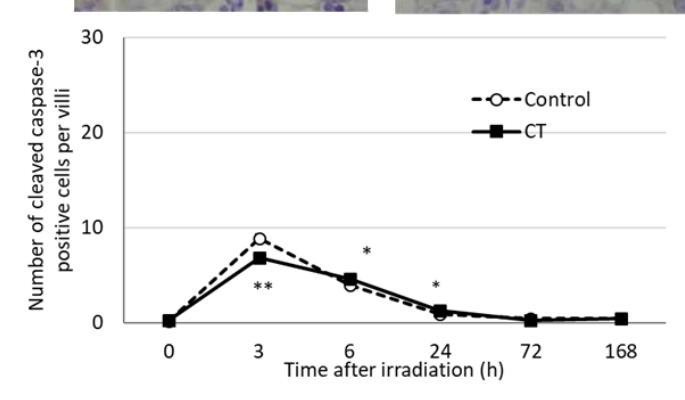


5 Gy
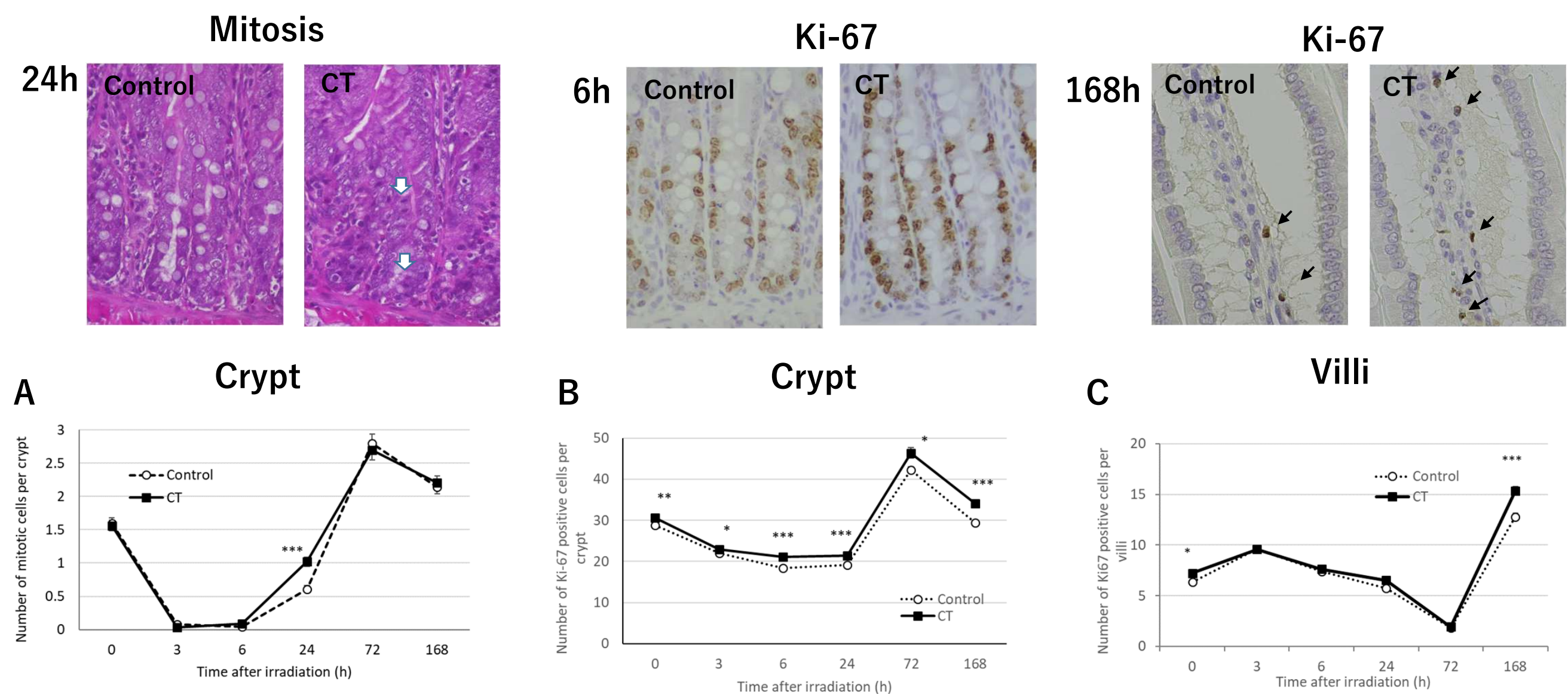

Fig.4 

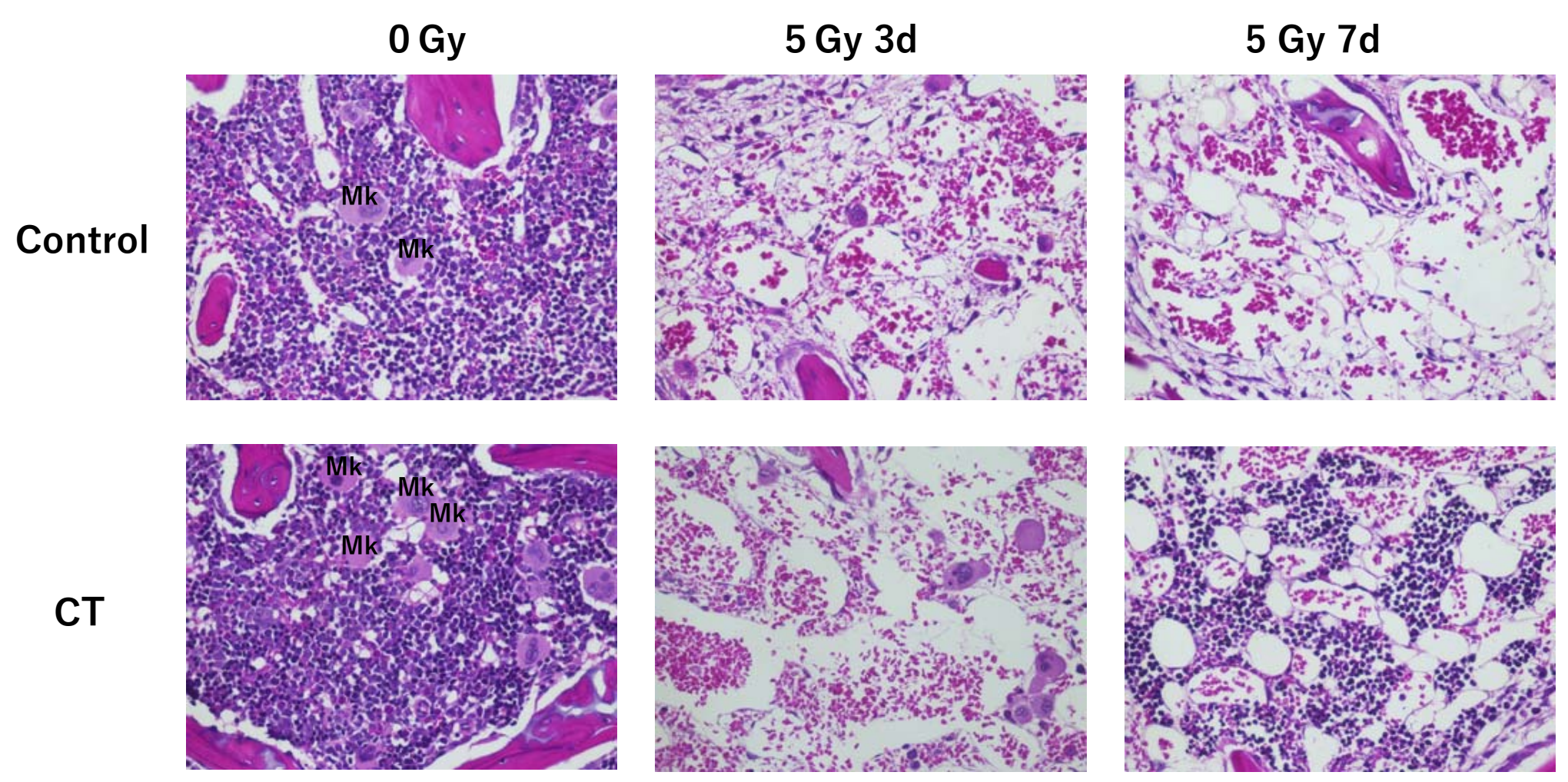

Bone marrow cells

Fig.5

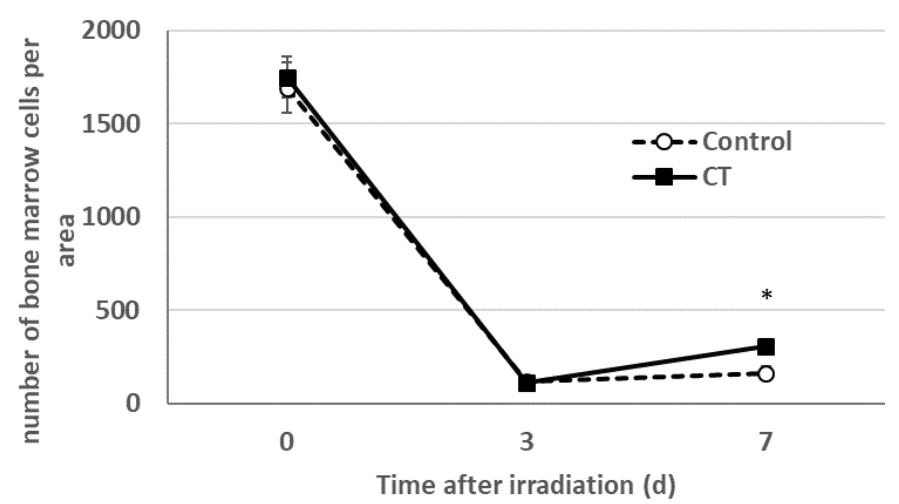


5Gy

TUNEL

Control

CT

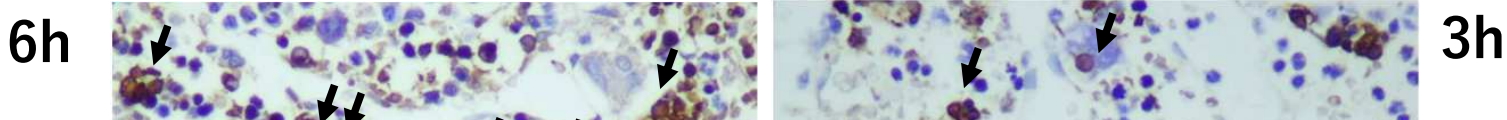

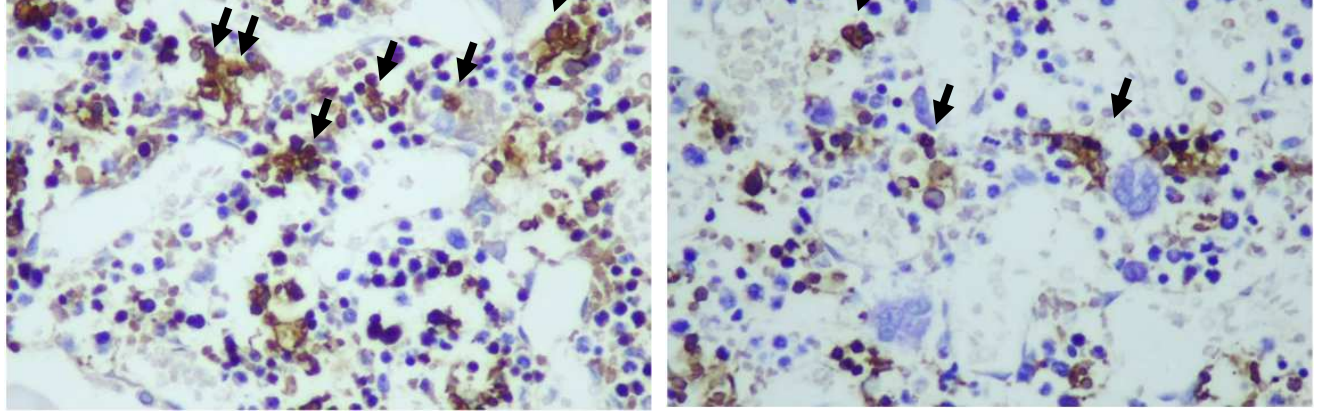

A

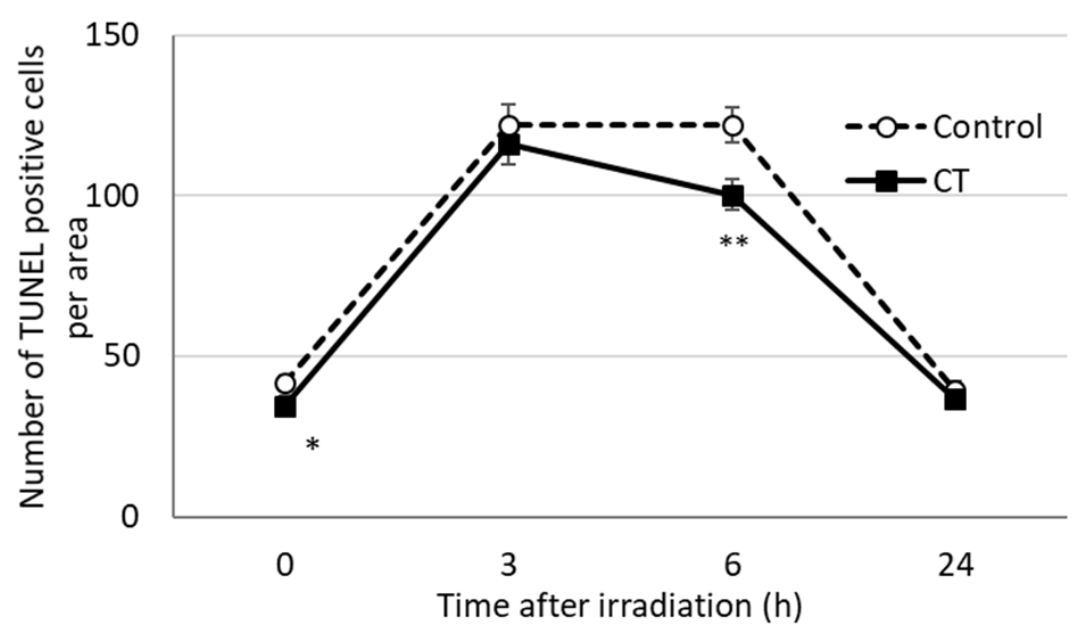

Fig.6

Cleaved caspase-3

Control

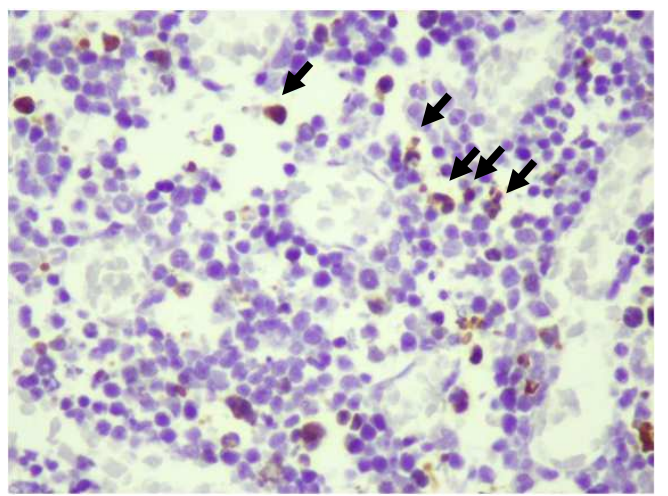

B
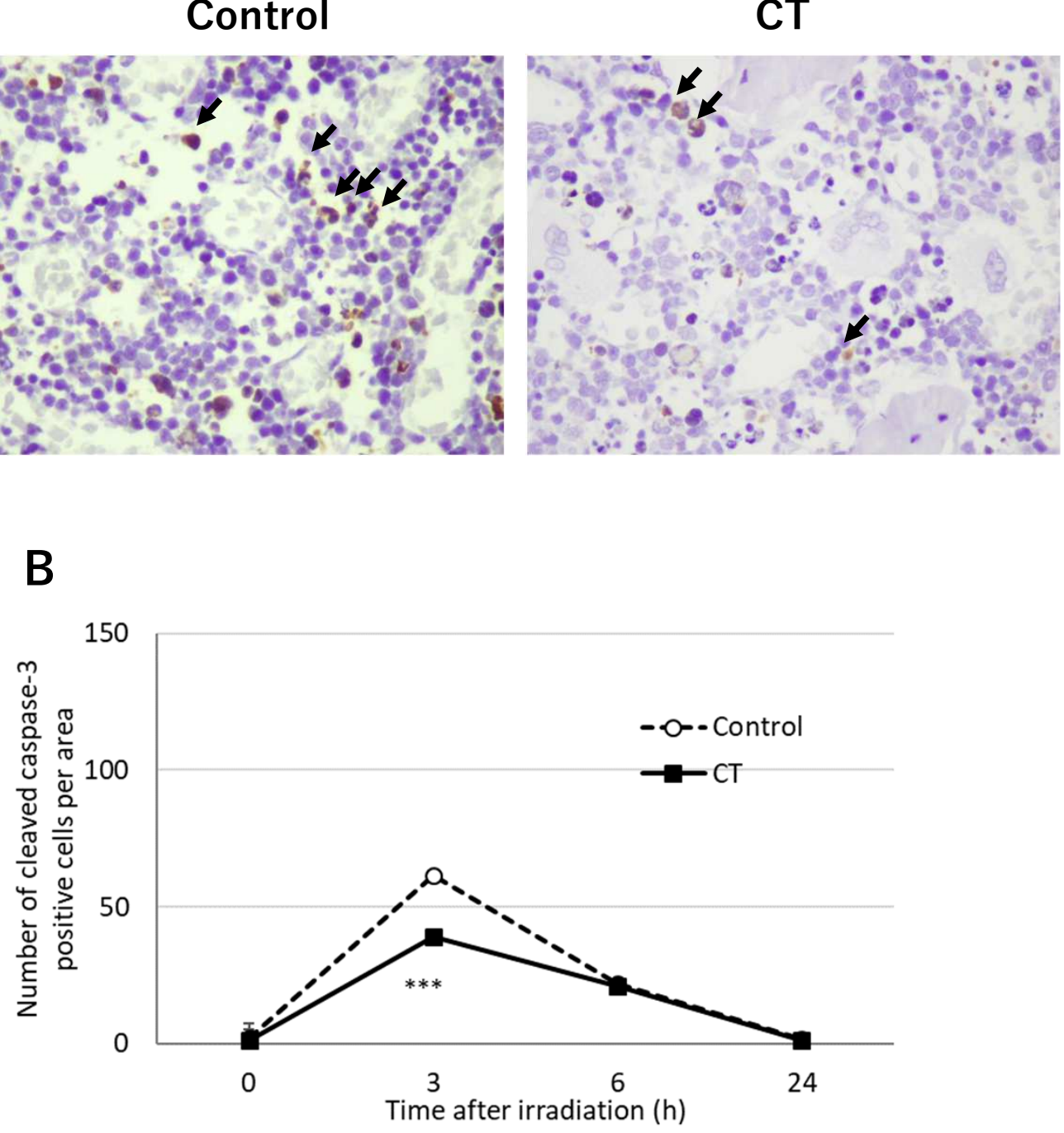

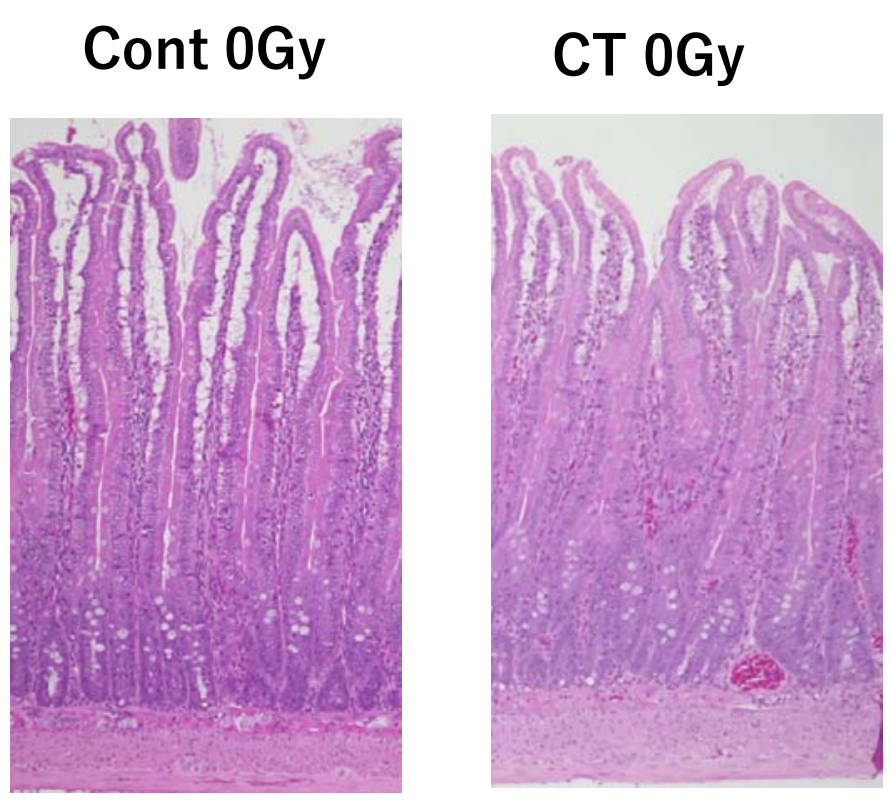

A

Supplement data Fig.1

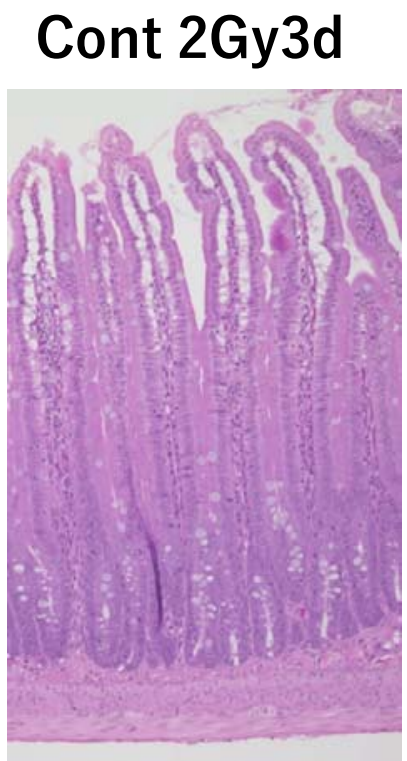

CT 2Gy3d

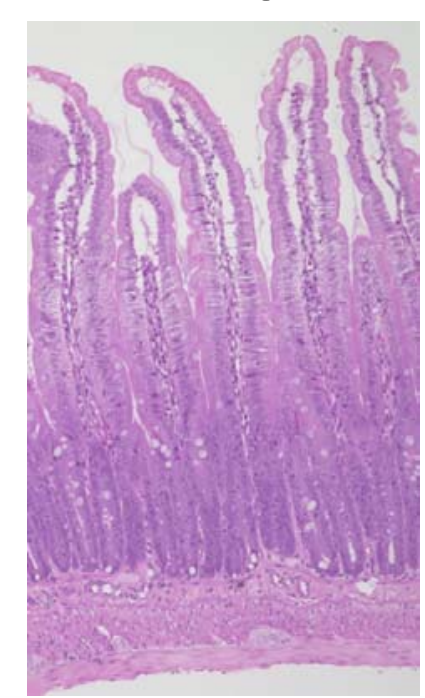

B

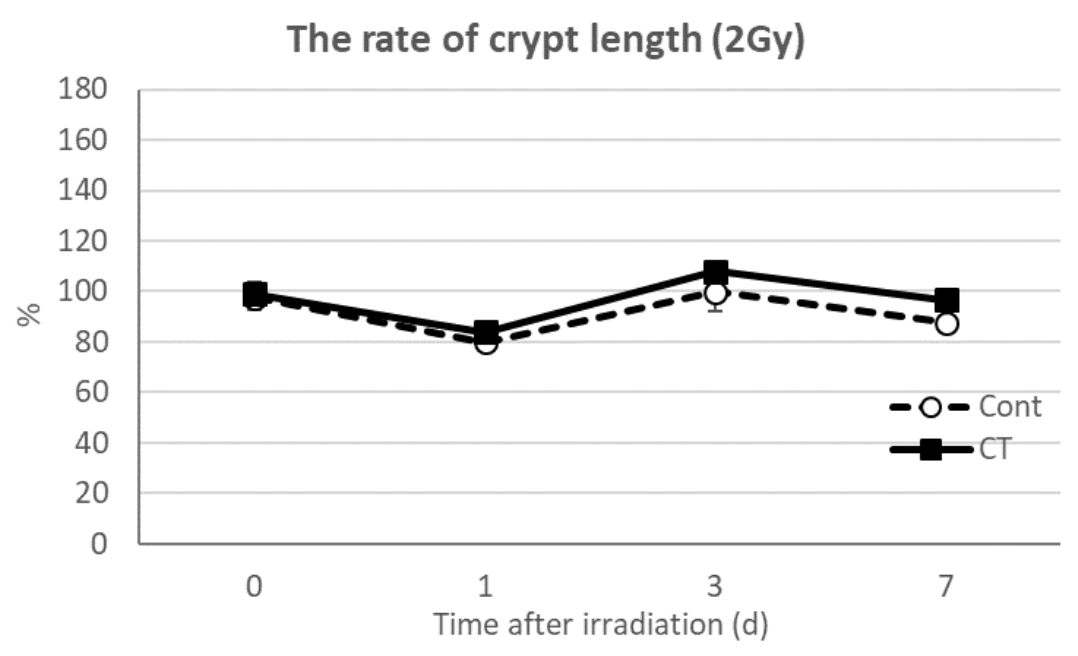


2 Gy
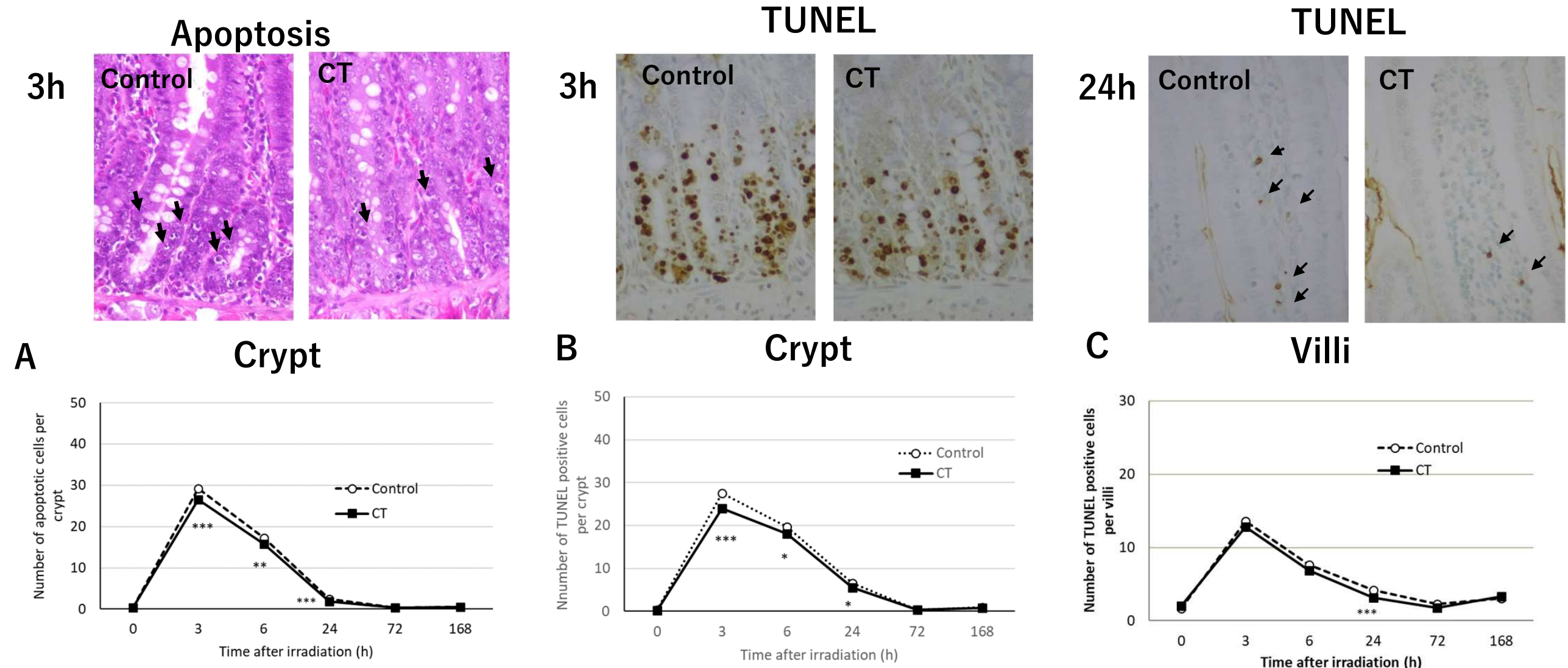
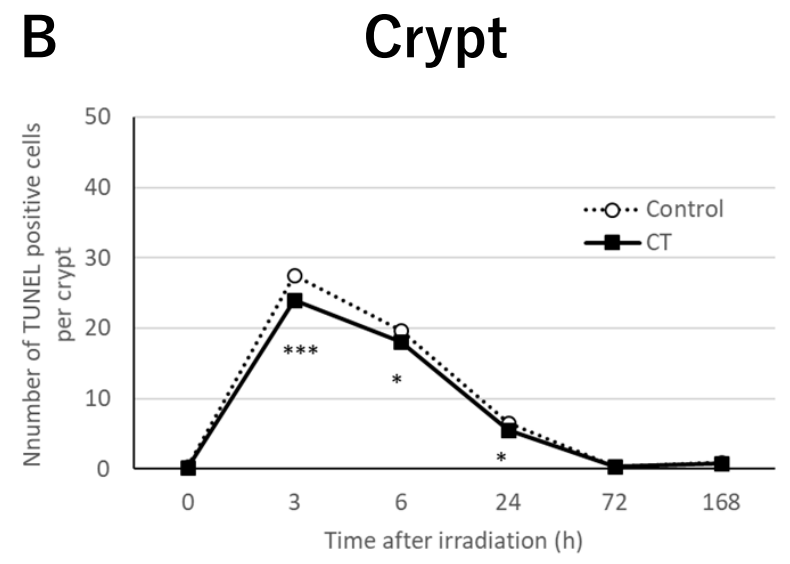

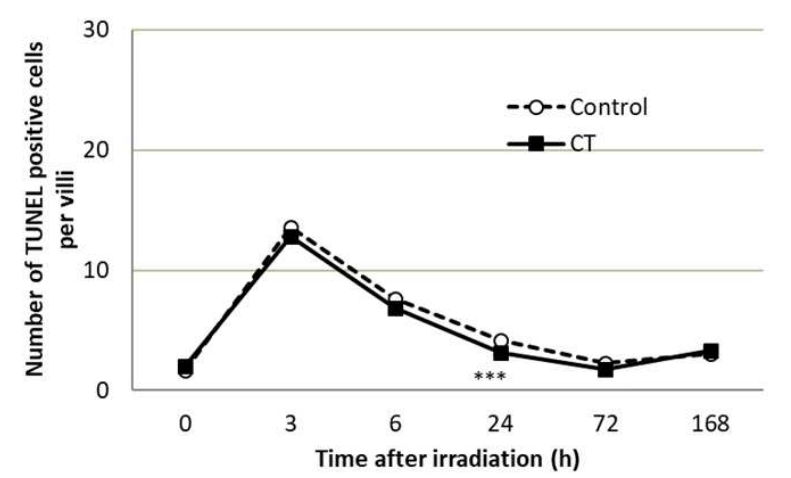

Supplement data Fig.2 
2 Gy

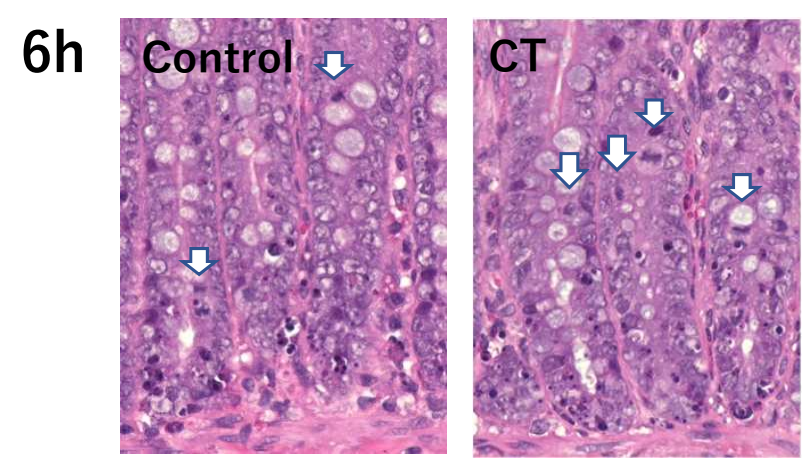

A

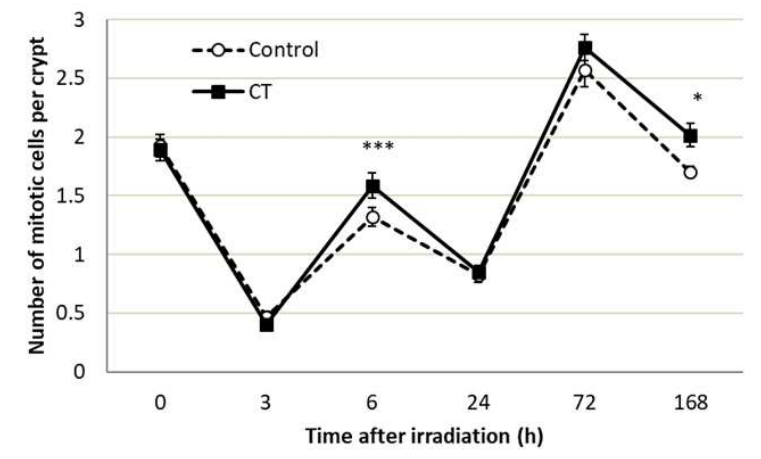

Ki-67

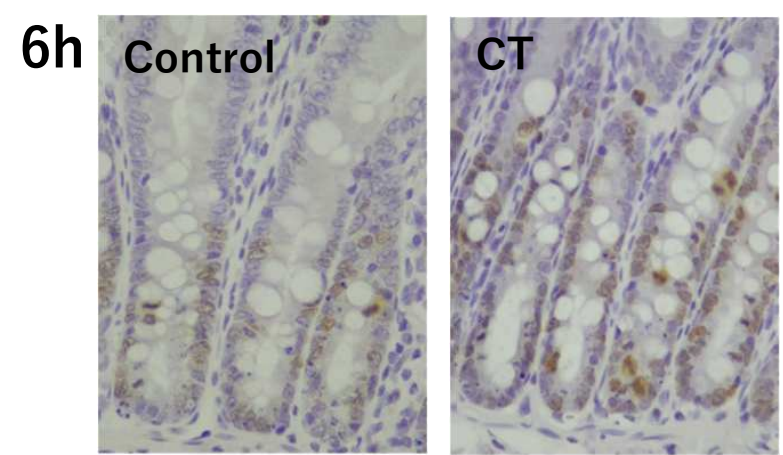

B

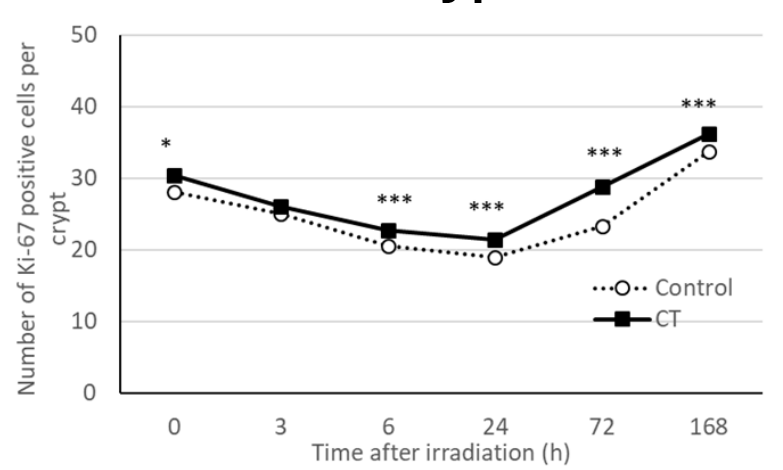

Ki-67

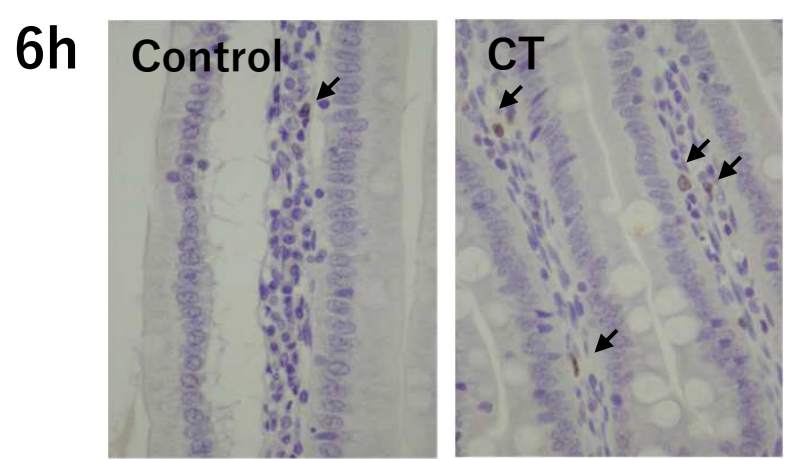

C

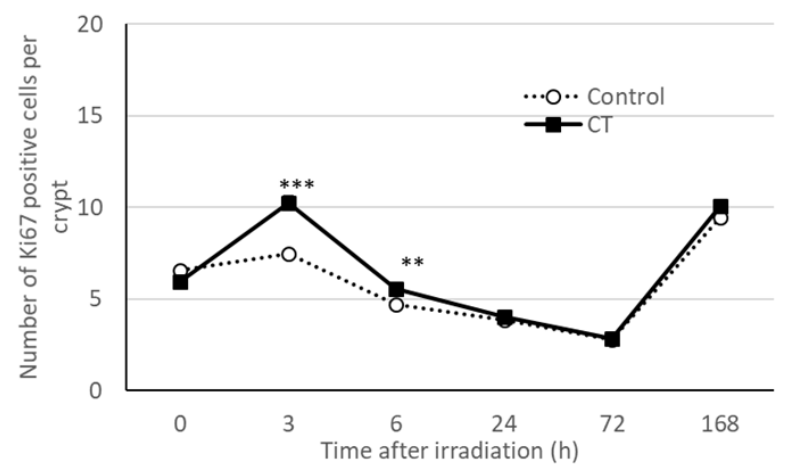

